\title{
Correction to: Can spinal surgery in England be saved from litigation: a review of 978 clinical negligence claims against the NHS
}

\author{
John T. Machin ${ }^{1}$. John Hardman² ${ }^{2}$. William Harrison ${ }^{3} \cdot$ Timothy W. R. Briggs ${ }^{4} \cdot$ Mike Hutton $^{5}$
}

Published online: 15 October 2018

๑) Springer-Verlag GmbH Germany, part of Springer Nature 2018

Correction to: European Spine Journal

https://doi.org/10.1007/s00586-018-5739-1

Unfortunately, the first author name was incorrectly published in the original publication. The complete correct name is given as below.

John T. Machin

The original article has been updated.

The original article can be found online at https://doi.org/10.1007/ s00586-018-5739-1.

John Hardman

John.hardman4@nhs.net

1 Nottingham University Hospitals NHS Trust, Chesterfield Royal Hospital NHS Foundation Trust, NHS Improvement, London, UK

2 Whittington Health NHS Trust, London, UK

3 Mersey Deanery, Liverpool, UK

4 The Royal National Orthopaedic Hospital (Stanmore) NHS Trust, NHS Improvement, London, UK

5 Royal Devon and Exeter NHS Foundation Trust, Exeter, UK 